\title{
The Innovation and Practice of the Training Mode of Functional Food Talents in Newly - Built Undergraduate Universities
}

\author{
Qingsong $L i^{1,2, a}$, Yao Lv ${ }^{1,2, b}$, Juntao $L i^{1,2, c}$, Jianfei Mu ${ }^{1,2, d}$, Ruokun $\mathrm{Yi}^{1,2, e}$ and \\ Xin Zhao ${ }^{1,2, f_{*}}$
}

${ }^{1}$ Chongqing Collaborative Innovation Center for Functional Food, Chongqing University of Education, Chongqing 400067, China

\author{
${ }^{2}$ School of Biological and Chemical Engineering,Chongqing University of Education, Chongqing \\ 400067, China

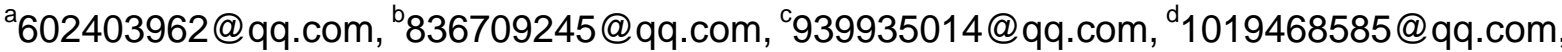

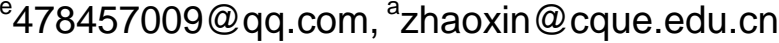

Keywords: Newly built undergraduate universities; Functional food; Talent training; Measures

\begin{abstract}
With the rapid development of China's economy, people's daily living standards and health needs are increasing, but also with the rapid development of functional food industry, new undergraduate universities of functional talent training model needs continuous improvement and innovation, so as to keep up with the pace of social development. Because of these new undergraduate colleges lack of school experience, resulting in the cultivation of functional food talent there are many problems. The talent training mode of the new undergraduate universities directly affects the reputation of the school, thus affecting the entire undergraduate colleges. In order to cultivate talents who can meet the needs of enterprises, this paper makes a deep research on the necessity, difficulty and solution of the cultivation mode of functional food in newly - built undergraduate colleges.
\end{abstract}

\section{Introduction}

From the development needs of China's three major industries, the development of functional food professionals in China's social and economic development of the objective requirements. From the development of the primary industry, with the rapid development of science and technology, China's primary industry from the previous traditional agriculture gradually to the development of high-tech agriculture, so the demand for talent from junior talent to senior personnel development Trend, this trend shows the demand for talent gradually increased. From the perspective of the development trend of the secondary industry, the economic globalization requires China to take the road of industrialization. The development of industrialization and major changes in industrial structure require a large number of practical operation, technological innovation, technology development and application in production, management and management. Research talent from the view of the development pattern of the tertiary industry, the rapid development of the tertiary industry, which is characterized by service industry, has become one of the main modes of global economic development. The tertiary industry demands more attention to the social sciences and the natural sciences, the theoretical knowledge of the subject is relatively low, the relatively high practicality. From the above three major trends in the development of the industry compared to the tertiary industry demand for talent is more prominent. With the rapid development of China's economy, people's demand for quality of life is getting higher and higher, a lot of people pay special attention to the maintenance of the body, so functional food talents play an important role in the development of our country [1].

\section{The Requirement of Newly Built Undergraduate Universities' Development}

To the rapid development of new undergraduate colleges, need to cultivate more talented people. Now our country is extremely lack of ability to adapt to strong functional food professionals, so the 
new undergraduate universities should be based on the training of personnel, functional food cultivation of high-quality talent. To create new undergraduate colleges and universities to play an innovative role in promoting new undergraduate colleges in the field of innovation and make more contributions. Hu Jintao, general secretary of Tsinghua University in the centennial of the time said that China's undergraduate universities to enhance the original capacity of innovation on the basis of absorption of scientific research universities and enterprise innovation, with the promotion of undergraduate universities innovation. With the development of higher education in our country, a large number of specialized schools in China have been reorganized into undergraduate colleges. However, these undergraduate universities in the transformation process, because of less experience, short time, the emergence of the teaching equipment is not complete, the weak teachers and other issues. Moreover, the new undergraduate college graduates in the employment and mature undergraduate college graduates compared to a far cry. The above problems with the personnel training model has a great relationship. Newly - built colleges and universities should recognize the current employment situation, improve the teaching level in all directions, form the unique characteristics of running a school, update the mode of personnel training, improve the quality of personnel training and promote the rapid development of new undergraduate colleges [2].

\section{The Employment Demand of Graduates}

In recent years, the major colleges and universities continue to enroll students, leading to an annual increase in the number of graduates, thus, the employment of college students is increasingly difficult problem. The main reason for the difficulty of college students' employment is the contradiction between the needs of the society and the quality of college students. Today, the rapid development of society, social needs of talent also will be enhanced; the need is all-round development, high-quality personnel. Society is developing rapidly, but the teaching mode of the new undergraduate colleges is relatively backward, leading to the college students cannot be quickly adapted to society, society cannot be met. In today's society, the demand for talent is not only the richness of theoretical knowledge, but also the practical application of the ability and theoretical knowledge of the combination of high-quality talent. Newly built undergraduate colleges and universities started from the theoretical knowledge as the traditional teaching way, thus neglected the university student practical application ability. In recent years, every graduation season will face graduation difficult, employment difficult problem. Therefore, in order to solve the employment problem of graduates, we need to improve the traditional undergraduate colleges teaching model, but also continue to strengthen the training of functional food professionals [3].

\section{The Qualities Functional Food Talents Should Possess}

Functional food is a food with specific nutritional health functions, it is to regulate the body's function, but also for a particular human consumption, but not for the purpose of treatment of food. Functional foods include: anti-aging and regulate the body nerve endings, nerve center, uptake and absorption of food; regulation of hematopoietic function, prevent platelet aggregation, control cholesterol food; to prevent constipation, coronary heart disease, diabetes, hypertension and other diseases Of food; enhance immunity and activate the lymphatic system of food. Functional food is the human body does not produce any chronic, subacute and acute hazards of food.

\section{Pay Attention to Partialness of Functional Food Talents}

Specialized colleges and universities pay special attention to the cultivation of applied, basic talents, the training of personnel to meet the social needs of reality, talent training model focused on general and application-oriented, emphasizing the students practical skills and practical ability. The new undergraduate universities to cultivate more systematic grasp of the profession, the discipline necessary basic knowledge and basic theory, master the necessary professional knowledge, basic 
skills and methods, can be independently responsible for the actual work and professional-related and preliminary Scientific research ability of professionals, it requires students to have a solid theoretical foundation, a more complete theoretical system and higher vocational skills, teaching content focus on systematic, theoretical, rational color is more rich, the training of talent to lead the community Rapid development of demand [4].

\section{Restore Innovation of Functional Food Talent}

Functional food talent training not only to reconstruct the quality of ability, but also to reshape the innovative quality of special talents, these talents are just the key factor in the growth of innovative talents. Under the traditional education system, the education of the "talent" of the scores, ignoring the cultivation of students' innovative quality, resulting in students to produce skill learning goals, impulsive learning psychology, lack of perseverance, lack of courage to explore and pragmatic spirit; Students are content with the status quo, always self-centered, quit, weak, arrogant lofty; when the individual ideas and the public consciousness of disagreement, personal ideas blindly listen to the views of the masses, leading to students drift; Values by the impact of market economy, concerned about their own survival, no great goal, light and meaningless and lack of dedication. To the rapid development of new undergraduate universities, it should accurately grasp and reshape the innovative nature of functional food talent, which is conducive to promoting the rapid growth of innovative talents. Innovative talents should have the service of social responsibility, not afraid of setbacks will, good at cooperation of the endowment, rigorous and realistic morality and the pursuit of truth [5].

\section{The Difficulties of Training Functional Food Talent}

Simplex Training Mode. Teaching mode in our country is under the influence of traditional ideas, have experience of undergraduate colleges and universities are to take the training mode of elite education. But the newly built undergraduate colleges and universities have no experience, but also did not have the courage and innovation consciousness. In order to be able to operate, the newly built undergraduate colleges and universities are mostly in the traditional teaching mode, in the aspect of training talents are basically copying, does not have its own talent training pattern, causes our country on the newly built undergraduate colleges and universities personnel training mode is always in a backward state. Through the survey found, the newly built undergraduate colleges and universities for the cultivation of the talent too pursuit of academic convergence mode; In teaching basic knowledge system on the pursuit of science knowledge, systematic and integrity, more inclined to the cultivation of research talents; On the system of professional knowledge too much emphasis on "wide diameter, thick foundation", thus ignoring the practice oriented with the method of the application layer with the knowledge, technology and ability, lead to students of focusing, occupational, applied than professional orientation of higher vocational college students, and academic than research university. Newly built undergraduate colleges and universities will only his own ideas, are not willing to follow the scientific research universities, party and government agencies, communities, enterprises, social and other cooperation. Lead to can't keep up with the pace of the era of talent cultivation, cannot meet the actual demand of the society [6].

Weak Faculty. The teacher is our best enlightenment teacher, is the starting point of interest. Teachers, curriculum, teaching management are three main factors of undergraduate teaching; teachers are the most important point. To develop functional food talent, we need to improve the existing curriculum system, it needs our teachers know unit of choose and employ persons and the social standard to our professional talent demand, must grasp the forefront of technology and the latest knowledge in the area and the development trend of related enterprises and the status quo. Newly built undergraduate colleges and universities recruit teachers graduated in recent years, doctoral and master's graduate students, they are lack of education teaching experience, the lack of understanding of the relevant enterprises and for basic education, they are lack of practical skills. In order to cultivate high-quality talents in the field of functional food, you need on a regular basis to the 
undergraduate colleges and universities to train teachers, learning, to the relevant enterprises to research and practice, to experience personally the work. To master the basic knowledge of education and production, management, service line at the forefront of knowledge and professional skills, improve their teaching ability and level [7], lays a solid foundation for training high-quality talents in the field of functional food.

The Lack of Practical Training Mode. The ultimate goal of education and training in functional food is the requirement of college students professional ability are improved, such a goal need more perfect curriculum system as support. Although some newly built undergraduate colleges and universities have a functional food talent training goal, but I did not change is given priority to with subject curriculum system. Newly built undergraduate colleges and universities require students to learn both traditional discipline basic course, emerging professional courses and requirements, lead to the students study very hard, nothing in some of the courses of study. There's no point to too many professional courses, courses, lead to the students there are professional, but there's no special skill. Comprehensive training curriculum construction and implementation, experimental training curriculum innovation is relatively weak, not so sure [8] can make the students obtain ability quality. Newly built undergraduate colleges and universities are more pay attention to the study of textbook knowledge, is the lack of practical ability to act, this will seriously affect the cultivation of the talent of functional food.

\section{Measures of Cultivating Functional Food Talents}

Strengthen The Construction Of Teaching Staff. To strengthen the construction of teaching staff is the key of the functional food talent training; the teachers would increase the quality of personnel training. Newly built undergraduate colleges and universities in hiring teachers, should be outside the enterprise technology division as a part-time teachers, school and enterprise jointly set up courses, according to the demand of the enterprise post, together with the enterprise technology division of the functional food training courses, experiment and some related theory course of practical strong, common research teaching target, optimizing the teaching content, curriculum standard, rational utilization of curriculum resources. Newly built undergraduate colleges and universities should actively build platform, let the teachers actively to enterprise, achieve the objectives of the school and enterprise combined. Moreover, the school also constantly encourages teachers to practice, the enterprise to carry out the relevant issues of research, [9] to help teachers to obtain more abundant practical experience, not only to consolidate the theoretical knowledge, also enrich the teachers' practical experience, to build into a high ability of teachers. The construction of teaching staff should also practice ability, personal qualities, the combination of theoretical knowledge, to promote each other, mutual communion. School organize regular teachers to go abroad to study and exchange, to make them understand the trend of the development of the local undergraduate colleges and universities, enhance the comprehensive quality of itself, so as to improve the research level of teachers, promote the development of teaching work [10].

Improve the Theoretical Teaching System. In order to develop the new undergraduate colleges, we should change the traditional idea of education, and should regard talent cultivation as the goal of development; we should improve the theory teaching system. In order to adapt to the development of society, the theoretical teaching system should take the ability as the core, the social demand as the guide, the application and foundation of the theory teaching as the starting point, and clear the students need to master the capacity development needs and theoretical knowledge. The new undergraduate colleges and universities out of the compulsory courses also should be added to the background of enterprise application technology, professional courses connected to the professional courses, so that students can business needs outside the main line, the knowledge and practice, for the development of integrated skills to provide a more comprehensive, systematic technical principles and theoretical knowledge. Professional theory and the number of class hours of compression, the course is the degree of degree, the creation of professional courses, should be based on business needs 
of personnel to provide. In order to avoid the blindness of professional curriculum construction, in the development of personnel training program should be widely understood before the business talent, quality, ability, knowledge and other needs. But also to listen to graduates in practical work on the needs of the professional curriculum recommendations, always concerned about the undergraduate universities to cultivate the favorable experience of personnel, thus strengthening the theoretical system reform.

\section{Acknowledgements}

This study was supported by Construction Project of Chongqing Engineering Research Center (cstc2015yfpt_gcjsyjzx0027), Construction Project of Chongqing Collaborative Innovation Center for Functional Food (ccicff-rp-201610) and Program for Innovation Team Building at Institutions of Higher Education in Chongqing (CXTDX201601040), China.

\section{References}

[1] H.P. Zhou, How to cultivate the characteristics of personnel training in the newly - built universities, Manage. Explor. 2014 (2014) 38-39.

[2] L. Liu, An analysis of the training mode of cooperative innovation talents in newly - built universities, J. Shanxi Nor. Univ. 2015 (2015) 175-176.

[3] Z.D. Hu, Research on the cultivation of practical talents in new built universities, Educ. Occupat. 2015 (2015) 31-32.

[4] G.H. He, on the connotation construction of the college from the college to college - taking the chizhou college of anhui province as the subject, J. Chizhou Teach. Coll. 18 (2012) 52-62.

[5] W.Y Chen, Educational transformation from the perspective of university student evaluation, Educ. Deve. Res. 2012 (2012) 76-80.

[6] Z.C. Liu, J. Liu, Research on the orientation and training mode of talents training in newly - built undergraduate colleges - from the perspective of applied talents, Trade Union Forum 2013 (2013) 125-127.

[7] X.L. Jiang, X.F Yang, On the Teaching system of practical talents training in newly - built universities, Heilongjiang High. Educ. Res. Inst. 2012 (2012) 170-172.

[8] M. Deng, Exploration on the construction of application - oriented talents cultivation scheme in newly - built universities, Yunnan Nat. Univ. 2015 (2015) 211-215.

[9] Q.S. Li, C.F. Deng, G.J. Li, Y.L. Zhou, X. Zhao, A study on the reformation of multidisciplinary experiments and training courses - taking the specialty of food quality and safety (child nutrition and health) as an example in Chongqing University of Education, J. Shijiazhuang Vocat. Technol. Inst. 27 (2015) 67-70.

[10] J. Teng, J.F. Mu, D. Luo, Q.S. Li, On the internationalization of newly-built universities and colleges, teaching and research, Hebei Inst. Eng. Technol. 2016 (2012) 8-10. 